\title{
Metabolic Complications of Androgen Deprivation Therapy for Prostate Cancer
}

\author{
Philip J. Saylor ${ }^{*}$ and Matthew R. Smith ${ }^{\dagger}$ \\ Department of Oncology, Massachusetts General Hospital Cancer Center, Boston, Massachusetts
}

\begin{abstract}
Purpose-Androgen deprivation therapy has a variety of well recognized adverse effects including vasomotor flushing, loss of libido, fatigue, gynecomastia, anemia and osteoporosis. This review focuses on the more recently described metabolic complications of androgen deprivation therapy including obesity, insulin resistance and lipid alterations as well as the association of androgen deprivation therapy with diabetes and cardiovascular disease.
\end{abstract}

Materials and Methods-We reviewed the medical literature using the PubMed® search terms prostate cancer, androgen deprivation therapy, gonadotropin-releasing hormone agonists, obesity, insulin resistance, lipids, diabetes, cardiovascular disease and myocardial infarction. We provide a focused review and our perspective on the relevant literature.

Results-Androgen deprivation therapy decreases lean mass and increases fat mass. It also decreases insulin sensitivity while increasing low density lipoprotein cholesterol, high density lipoprotein cholesterol and triglycerides. Consistent with these adverse metabolic effects, androgen deprivation therapy may be associated with a greater incidence of diabetes and cardiovascular disease. Some of these androgen deprivation therapy related metabolic changes (obesity, insulin resistance and increased triglycerides) overlap with features of the metabolic syndrome. However, in contrast to the metabolic syndrome, androgen deprivation therapy increases subcutaneous fat and high density lipoprotein cholesterol.

Conclusions-Androgen deprivation therapy increases obesity, decreases insulin sensitivity and adversely alters lipid profiles. It may be associated with a greater incidence of diabetes and cardiovascular disease. The benefits of androgen deprivation therapy should be weighed against these and other potential harms. Little is known about the optimal strategy to mitigate the adverse metabolic effects of androgen deprivation therapy. Thus, we recommend an emphasis on existing strategies for screening and treatment that have been documented to reduce the risk of diabetes and cardiovascular disease in the general population.

\section{Keywords}

prostatic neoplasms; gonadotropin-releasing hormone agonists; cardiovascular diseases; diabetes mellitus; obesity

For most men the diagnosis of prostate cancer does not alter life expectancy. The contemporary 5-year relative survival for men with all stages of prostate cancer combined is $98.8 \% .^{1}$ With

\footnotetext{
*Correspondence: Department of Medical Oncology, Massachusetts General Hospital Cancer Center, 55 Fruit St., POB-2-221, Boston, Massachusetts 02114 (psaylor@partners.org).

${ }^{\dagger}$ Supported by a National Institutes of Health K24 Midcareer Investigator Award (5K24CA121990-02), and grants from the Prostate

Cancer Foundation and Lance Armstrong Foundation.
} 
these improvements in prostate cancer specific survival, consideration of treatment related morbidity has become increasingly important.

ADT can be accomplished with surgical castration (bilateral orchiectomy) or medical castration with $\mathrm{GnRH}$ agonist therapy and is an effective treatment for prostate cancer in a variety of clinical settings. GnRH agonists improve disease-free and overall survival when used in combination with primary radiation for locally advanced or high risk localized disease. ${ }^{2,3} \mathrm{ADT}$ alleviates bone pain and modestly prolongs survival when used for the palliation of metastatic disease. ${ }^{4}$ GnRH agonists have largely replaced bilateral orchiectomy for a variety of reasons including ease of administration, reversibility, and the cosmetic and psychological issues associated with orchiectomy.

GnRH agonist use has increased steadily during the last 2 decades. ${ }^{5,6}$ There is evidence for improved disease-free or overall survival for 1) the combination of GnRH agonist therapy with primary radiation for locally advanced or high risk disease ${ }^{2,3}$ and 2) adjuvant therapy for $\mathrm{pN} 1$ disease after prostatectomy. ${ }^{7}$ In addition, PSA monitoring after primary therapy for prostate cancer facilitates the detection of PSA recurrent disease long before such recurrences would have become clinically evident. PSA only recurrence after surgery or RT often leads to longterm ADT. Finally, some men opt for long-term ADT for localized disease as an alternative to radiation or surgery, an approach that has not been shown to improve survival compared to conservative management. ${ }^{8}$

Regardless of the indication GnRH agonist therapy produces a marked reduction in circulating testosterone and a number of associated changes. It is now known to cause detrimental changes in body composition, lipid profile and insulin sensitivity. GnRH agonists are also associated with greater risks of incident diabetes and cardiovascular disease. This review summarizes the evidence for these recently recognized metabolic complications of ADT, and discusses established and emerging strategies to prevent related morbidity.

\section{OBESITY AND SARCOPENIA}

Obesity is an epidemic worldwide. The World Health Organization estimates that worldwide more than 1.7 billion people are overweight (BMI between 25.0 and $29.9 \mathrm{~kg} / \mathrm{m}^{2}$ ) and 310 million are obese (BMI $30.0 \mathrm{~kg} / \mathrm{m}^{2}$ or greater). Rates of obesity in the developing world have tripled in the last 20 years..$^{9}$ Obesity is particularly prevalent in the United States and other Western countries. Approximately 72 million American adults, including $33.3 \%$ of men, were obese as of $2007 .^{10}$

Androgens are important determinants of body composition as they promote lean body mass over fat mass. ${ }^{11}$ This can be therapeutically useful as exogenous testosterone replacement increases lean body mass in men who are hypogonadal due to medical comorbidities such as age or HIV infection. ${ }^{12,13}$

Conversely ADT increases fat mass and decreases lean body mass. ${ }^{14,15}$ Sarcopenic obesity is a relatively new term for the combination of excess weight and reduced muscle mass or strength. ${ }^{16}$ One early prospective study examined ADT induced changes in body composition by following 40 men with locally advanced nonmetastatic prostate cancer from initiation through the first year of GnRH agonist therapy. ${ }^{15}$ During 1 year weight increased by $2.4 \%$ $( \pm 0.8 \%, p=0.005)$, percentage fat body mass increased by $9.4 \%( \pm 1.7 \%, p<0.001)$ and percentage lean body mass decreased by $2.7 \%( \pm 0.5 \%, \mathrm{p}<0.001)$. Similarly a larger study of 79 men with nonmetastatic prostate cancer also showed significant weight gain $(1.8 \% \pm 0.5 \%$, $\mathrm{p}<0.001)$ during 1 year of ADT. ${ }^{17}$ Percentage fat mass increased $(11.0 \% \pm 1.7 \%)$ and percentage lean mass decreased $(3.8 \% \pm 0.6 \%)$. Another prospective study of 26 men receiving 
12 months of GnRH agonist therapy found that fat mass increased by $11.2 \%( \pm 1.5 \%, \mathrm{p}<0.001)$ and lean body mass decreased by $3.6 \%( \pm 0.5 \%, \mathrm{p}<0.001) .{ }^{18}$

Fat accumulation during treatment with GnRH agonists is primarily subcutaneous fat (fig. 1). In contrast, intra-abdominal fat generally does not change significantly. In 1 study subcutaneous fat area by cross-sectional imaging increased by $11.1 \%( \pm 3.4 \%, \mathrm{p}=0.003)$ during the first year of ADT while intra-abdominal fat area did not change significantly. ${ }^{15}$ In another report subcutaneous fat accounted for $94 \%$ of the observed $16.5 \%( \pm 2.6 \%, \mathrm{p}<0.001)$ increase in abdominal fat area. ${ }^{19}$

Treatment related alterations in body composition are early adverse effects. Two studies have demonstrated significant changes within the first 3 months of therapy. In 1 study 3 months of ADT caused significant increases in fat mass and circulating insulin in 22 treatment naïve men.

${ }^{20}$ In another study 12 weeks of combined androgen blockade with a GnRH agonist and bicalutamide in 25 men caused a $4.3 \%( \pm 1.3 \%, \mathrm{p}=0.002)$ increase in fat body mass. ${ }^{21} \mathrm{~A}$ prospective study of 65 men receiving 12 months of therapy demonstrated that a longer duration of previous treatment predicted smaller changes in body composition, highlighting the dynamic changes early in treatment. ${ }^{22}$

Little is known about the best strategy to prevent treatment related changes in body composition. One study randomized 155 men to 3 times per week resistance exercise or to a waiting list control group upon initiation of ADT. After 3 months of ADT, body composition did not differ between the groups. ${ }^{23}$ The resistance training group did benefit from less fatigue, higher quality of life and higher levels of muscular fitness.

\section{LIPID ALTERATIONS}

GnRH agonists cause several characteristic changes in serum lipids. Multiple studies have demonstrated increases primarily in total cholesterol, triglycerides and HDL. ${ }^{15,24,25}$ An early study of 26 patients receiving 24 weeks of the GnRH agonist leuprolide acetate for benign prostatic hyperplasia demonstrated increases in total cholesterol $(10.6 \%, \mathrm{p}=0.003)$, HDL $(8.2 \%, \mathrm{p}=0.052)$ and triglycerides $(26.9 \%, \mathrm{p}=0.050)$. LDL did not change significantly. ${ }^{25}$ One year of GnRH agonist therapy in a group of 40 men with prostate cancer was later found to cause significant increases in cholesterol (9.0\%), HDL (11.3\%), LDL (7.3\%) and triglycerides $(26.5 \%) .{ }^{15}$ In another study men experienced significant increases in total cholesterol and HDL during the first 3 months of GnRH agonist treatment. ${ }^{24}$

Awareness of the potential for these changes can prompt appropriate management and facilitate $\mathrm{CV}$ risk reduction. Large cohort analyses show a strong, continuous, graded relationship between serum cholesterol and cardiovascular mortality independent of other coronary risk factors such as blood pressure and smoking status. ${ }^{26,27}$

The NCEP ATP-III provides guidelines for the evaluation and treatment of high cholesterol in the general population. ${ }^{28}$ These guidelines outline the assessment of CHD risk in each patient, the assignment of an appropriate LDL target for each patient and appropriate interventions to achieve the LDL target. In addition to diet and lifestyle interventions, statin drugs are the mainstays of pharmacological management and have been shown in a large meta-analysis to reduce all cause mortality by approximately $16 \% .^{29}$

\section{INSULIN RESISTANCE}

Insulin resistance is a metabolic abnormality that accompanies diabetes, prediabetes and obesity. It is an independent risk factor for cardiovascular disease and is present in about a fourth of adults in the general population. ${ }^{30,31}$ Impaired insulin sensitivity in response to $\mathrm{GnRH}$ 
agonists is an early development, and is likely relevant to the risks of diabetes, coronary artery disease, myocardial infarction and sudden death. ${ }^{32}$ Men with prostate cancer are further burdened as GnRH agonists increase fasting insulin levels $\mathrm{s}^{20,24}$ and decrease sensitivity to insulin. ${ }^{19,21}$

Insulin resistance is illustrated in figure 2. While serum glucose curves during the OGTT are identical after 12 weeks of combined androgen blockade, insulin levels significantly increase from baseline. ${ }^{19}$ In a prospective study of 22 men receiving $\mathrm{GnRH}$ treatment for prostate cancer, median fasting serum insulin increased progressively from 11.8 at baseline to $15.1 \mathrm{mU} /$ $1(\mathrm{p}=0.021)$ at 1 month and to $19.3 \mathrm{mU} / \mathrm{l}(\mathrm{p}=0.020)$ at 3 months. ${ }^{20} \mathrm{In}$ a 3 -month study of 16 men initiating $\mathrm{GnRH}$ agonist treatment, fasting insulin levels nearly doubled from $6.89( \pm 4.84)$ to $11.34( \pm 8.16) \mathrm{mU} / \mathrm{l}^{24}$

A prospective 12-week study of 25 men receiving combined androgen blockade with a GnRH agonist and bicalutamide demonstrated a $13 \%$ decrease $(\mathrm{p}=0.02)$ in the insulin sensitivity index (calculated from results of the oral glucose tolerance test ${ }^{33}$ ). ${ }^{21}$ Insulin sensitivity by homeostatic model assessment decreased similarly. Fasting plasma insulin levels increased by $26 \%(\mathrm{p}=0.04)$ and mean glycosylated hemoglobin also increased significantly $(\mathrm{p}<0.001)$.

The ADA recommends that patients with impaired glucose tolerance or impaired fasting glucose (IGT or IFG, see Appendix) should be given counseling on weight loss of 5\% to $10 \%$ of body weight and on increasing physical activity to at least 150 minutes per week of moderate activity such as walking. ${ }^{34}$

\section{THE METABOLIC SYNDROME}

The metabolic syndrome is a cluster of $\mathrm{CV}$ risk factors that seem to center on insulin resistance. 35,36 Diagnosis of the syndrome requires some combination of low HDL, increased waist circumference, increased triglycerides, increased fasting glucose and hypertension. Consistent with the observations from prospective studies that ADT increases abdominal fat area and triglycerides, and decreases insulin sensitivity, cross-sectional studies have shown that men receiving ADT are more likely to meet the diagnostic criteria for the syndrome. ${ }^{18,37}$

Although the metabolic alterations of ADT share some of the features of the classically defined metabolic syndrome, there are important differences (table 1). Distinct from the metabolic syndrome, ADT associated changes feature an increased HDL. In addition, ADT has been shown in 2 prospective studies to cause increases in subcutaneous rather than visceral abdominal fat. ${ }^{15,18}$ Finally, the metabolic syndrome is associated with low levels of adiponectin ${ }^{38}$ and an increased C-reactive protein ${ }^{39}$ while $\mathrm{GnRH}$ agonists are associated with increased adiponectin and unchanged C-reactive protein levels. ${ }^{18,19}$

The concept of the metabolic syndrome in any population has recently been called into question as it does not dependably add to the predictive value of traditional risk factors for diabetes or cardiovascular disease ${ }^{35,36}$ In a recent review of 2 large prospective studies that included a combined total of 6,955 patients, the diagnosis of metabolic syndrome was no better at predicting incident diabetes than the presence of increased FPG $(110 \mathrm{mg} / \mathrm{dl}$ or greater $) .{ }^{40}$ The ADA has recommended the evaluation and treatment of all cardiovascular disease risk factors regardless of whether a patient meets the diagnostic criteria for the metabolic syndrome. ${ }^{36}$ Despite some overlap the metabolic changes that accompany GnRH agonist therapy are distinct from the classically defined metabolic syndrome. These differences and the doubtful prognostic value of the syndrome itself contraindicate its use in the clinical care of men receiving $\mathrm{ADT}$. 


\section{DIABETES}

Insulin sensitivity decreases as BMI increases. ${ }^{41}$ Obesity and insulin resistance are strongly associated with type 2 diabetes. ${ }^{42}$ Prompted by their prospective observation that GnRH agonists increase fat mass and decrease insulin sensitivity, Keating et al conducted a large population based study to evaluate the potential relationship between ADT and the new diagnosis of diabetes. ${ }^{32}$ They used SEER and Medicare databases to study the records of 73,196 men 66 years old or older who had been diagnosed with locoregional prostate cancer between 1992 and 1999 and observed through 2001. Among the third of those men who received a GnRH agonist during the followup period, the adjusted hazard ratio was higher for incident diabetes (HR 1.44, $\mathrm{p}<0.001$ ). The 7\% who underwent bilateral orchiectomy were also significantly more likely to have diabetes (AHR 1.34). Similarly analysis of a Canadian database including approximately 20,000 men 66 years old or older treated for prostate cancer found that diabetes was $16 \%$ more likely to develop in these men than in matched controls in a preliminary report. ${ }^{43}$ Although the ADA does not specifically list hypogonadism as a risk factor for diabetes, we recommend treating all men receiving ADT as high risk individuals based on recent data about the effect of ADT on insulin sensitivity 19,21 and its association with diabetes (see Appendix for adapted ADA recommendations). ${ }^{32,34,43}$

\section{CARDIOVASCULAR MORBIDITY AND MORTALITY}

Given that ADT associated obesity, insulin resistance and increased triglycerides suggest a greater risk of cardiovascular disease, Keating et al also evaluated the relationship between ADT and new cardiovascular disease. ${ }^{32}$ The men who received a GnRH agonist had a higher incidence of CHD (HR 1.16, $\mathrm{p}<0.001$ ), myocardial infarction (HR 1.11, p = 0.03) and ventricular arrhythmia/SCD (HR 1.16, $\mathrm{p}=0.004$; note: sudden cardiac death does not necessarily result in patient death). Notably the excess risk of new diabetes (HR 1.44) was approximately 3 times that of new cardiovascular disease (HR 1.16, fig. 3). Risks for coronary heart disease, myocardial infarction and sudden cardiac death were not increased in the men who underwent bilateral orchiectomy.

Some but not all studies have confirmed an association between ADT and greater risk of cardiovascular disease (tables 2 and 3). Retrospective population based analysis of almost 23,000 men with prostate cancer similarly showed that ADT caused a 20\% increase in the risk of serious cardiovascular morbidity at 1 year. ${ }^{44}$ In contrast, a preliminary report of analyses of a Canadian database of approximately 20,000 men 66 years old or older treated for prostate cancer showed no increase in the risk of acute myocardial infarction. ${ }^{43}$ The absence of an association between ADT and risk of cardiovascular events in this study may reflect inadequate power to detect a numerically modest effect, different methods of ascertainment of new cardiovascular disease or differences in the population studied.

The possible association between GnRH agonists and cardiovascular mortality has been the subject of several analyses (tables 2 and 3). Although ADT is significantly associated with incident diabetes and cardiovascular morbidity, these trials do not consistently describe a significant relationship between ADT and cardiovascular death.

Three large RTOG trials have shown comparable cardiovascular mortality regardless of ADT assignment. RTOG 85-31 compared radiation alone to radiation with indefinite ADT in a group of more than 900 men with prostate cancer and unfavorable prognoses due to T3 tumors or nodal involvement. ${ }^{45} \mathrm{~A}$ total of 117 cardiovascular related deaths occurred during the 8.1-year followup. ${ }^{46}$ Cardiovascular mortality was $8.4 \%$ with indefinite ADT and $11.4 \%$ when ADT was started only on evidence of recurrence, a nonsignificant difference. 
In RTOG 86-10, 456 men with locally advanced prostate cancer were randomized to radiation alone or to radiation with 4 months of neoadjuvant combined androgen blockade. ${ }^{47}$ Of the 348 deaths during 10 years of followup, 57 were classified as cardiovascular deaths. There was no significant difference in cardiovascular mortality between the radiation alone group (11\%) and the combined therapy group ( $14 \%, \mathrm{p}=0.32$ for the comparison).

In RTOG 92-02, 1,554 men with locally advanced prostate cancer were randomized to radiation with 4 or 28 months of ADT with a GnRH agonist. ${ }^{48}$ There were 185 cardiovascular related deaths during the 8.1-year followup. The 5-year cardiovascular mortality was $5.9 \%$ with long duration ADT and 4.8\% with short duration ADT (HR 1.09, p = 0.58), a nonsignificant difference. The absence of a significant difference between treatment groups suggested no increase in cardiovascular mortality risk with increasing duration of GnRH agonist treatment. Well described cardiac risk factors such as age, diabetes and personal history of coronary artery disease maintained their predictive value.

EORTC trial 30891 showed no difference in cardiovascular mortality based on timing of ADT.

49 This trial enrolled 985 men with prostate cancer not suitable for local treatment and randomized them to ADT either immediately, or deferred until symptomatic progression or serious complications. The median time from randomization to the start of treatment in the deferred group was 7 years. There were 185 deaths due to cardiovascular disease and 193 due to prostate cancer during the 7.8 years of followup. Of those deaths 88 (17.9\%) occurred in the immediate ADT group and 97 (19.7\%) occurred in the deferred ADT group, a nonsignificant difference. The overall survival hazard ratio was 1.25 (95\% CI 1.05-1.48) favoring immediate treatment.

The CaPSURE database has been the only source to show a statistically significant ADT attributable risk of cardiovascular death. ${ }^{50}$ For the 3,262 men in the database who were treated with radical prostatectomy, older age (continuous variable, AHR 1.07; $\mathrm{p}=0.003$ ) and neoadjuvant ADT (AHR 2.6, p = 0.002) were the only factors independently associated with death from cardiovascular causes. In contrast, baseline heart disease and diabetes were not. ADT caused a trend toward increased cardiovascular death at 5 years in men of all ages. This finding was statistically significant in men 65 years old or older, in whom the incidence of cardiovascular death was $5.5 \%$ with ADT and $2.0 \%$ without (61 total events, $p=0.002$ ). Similar differences were observed in patients treated with radiation but were not statistically significant.

Combined analysis of 3 randomized trials of men treated with radiation for intermediate or high risk prostate cancer suggested that men 65 years old or older treated with 6 months of ADT experienced earlier onset of fatal myocardial infarction than those who did not receive ADT. ${ }^{51}$ The statistical methods used to reach this conclusion have been questioned, particularly with reference to the small number of events (18 in the ADT group and 16 in the control group). 52

There is no convincing evidence that ADT is associated with greater cardiovascular mortality. This absence of a persuasive association between ADT and cardiovascular mortality is consistent with the modest relative risk for new cardiovascular disease in men receiving GnRH agonists for prostate cancer. For example, in a large population based study Keating et al observed an excess risk of hospital admission for MI of $11 \%$ (fig. 3). ${ }^{32}$ Assuming this is a reliable estimate of the risk of MI, the excess risk of cardiovascular mortality would be expected to be well below $11 \%$. Retrospective analysis of relatively small studies would generally be inadequate to detect such a small increase in cardiovascular mortality. Exploratory analysis of smaller studies with low numbers of events could be subject to chance observations. ${ }^{52}$ 


\title{
CONCLUSIONS AND RECOMMENDATIONS
}

Diabetes and cardiovascular disease are among the leading causes of noncancer death in patients with cancer, accounting for $35 \%$ of noncancer deaths in 1 analysis. ${ }^{53} \mathrm{GnRH}$ agonists, widely used for the treatment of prostate cancer, are associated with several metabolic changes (obesity, insulin resistance and lipid alterations), and an increased risk of diabetes and cardiovascular events. Therefore, it is important to understand and manage those metabolic changes. In the absence of high level evidence specific to men with prostate cancer, we recommend following well established guidelines on the screening and management of these changes in the general population. ADA screening recommendations for prediabetes and diabetes are described in the Appendix.

Optimal management strategies for the GnRH associated changes in body composition and insulin resistance have not yet been defined. According to the ATP-III the 2 general goals when managing insulin resistance are to treat the underlying cause when possible and to treat cardiovascular risk factors individually if they persist despite lifestyle modifications. ${ }^{54}$ The ADA specifically recommends counseling patients with IGT or IFG to strive for 5\% to 10\% weight loss and at least 150 minutes per week of moderate exercise.

In men and women without cancer lifestyle intervention targeting weight loss and increased physical activity was shown to be approximately twice as effective as metformin at reducing the risk of incident diabetes ${ }^{55}$ Randomized study of intensive lifestyle intervention to improve insulin sensitivity and markers of cardiovascular disease in men receiving GnRH agonists is ongoing. Resistance exercise training during GnRH agonist treatment does not prevent weight gain but has been shown to decrease treatment related fatigue, and improve quality of life and muscular fitness.

Appropriately aggressive management of hyper-lipidemia has been effective in the general management of cardiovascular disease and should likely be a component of medical care for men receiving ADT for prostate cancer. The NCEP ATP-III guidelines describe the assignment of a risk adjusted LDL target and first line use of statins when lifestyle interventions are inadequate to reach that target. Toremifene has shown promise for the management of GnRH agonist associated lipid changes but its effect on cardiovascular outcomes has not yet been studied.

Physicians and patients should consider the metabolic side effects, and risk of diabetes and cardiovascular disease when making treatment decisions about ADT. Clinicians should educate patients about these risks as they must be balanced against the potential benefits of therapy. It is reasonable to adopt strategies to decrease the risk of diabetes and cardiovascular disease. This includes screening for prediabetes/diabetes according to ADA guidelines, lifestyle modifications according to ADA guidelines and management of lipids according to NCEP ATP III guidelines. Finally, physicians and patients alike should support survivorship research to further our understanding and improve our management of these important issues.

\section{Abbreviations and Acronyms}

\author{
ADA American Diabetes Association \\ ADT androgen deprivation therapy \\ AHR adjusted hazard ratio \\ BMI body mass index \\ CaPSURE Cancer of the Prostate Strategic Urologic Research Endeavor
}




$\begin{array}{ll}\text { CHD } & \text { coronary heart disease } \\ \text { CV } & \text { cardiovascular } \\ \text { EORTC } & \text { European Organization for the Research and Treatment of Cancer } \\ \text { FPG } & \text { fasting plasma glucose } \\ \text { GnRH } & \text { gonadotropin-releasing hormone } \\ \text { HDL } & \text { high density lipoprotein } \\ \text { IFG } & \text { impaired fasting glucose } \\ \text { IGT } & \text { impaired glucose tolerance } \\ \text { LDL } & \text { low density lipoprotein } \\ \text { MI } & \text { myocardial infarction } \\ \text { NCEP ATP III } & \text { National Cholesterol Education Program Adult Treatment Panel III } \\ \text { OGTT } & \text { oral glucose tolerance test } \\ \text { PSA } & \text { prostate specific antigen } \\ \text { RT } & \text { radiation therapy } \\ \text { RTOG } & \text { Radiation Therapy Oncology Group } \\ \text { SCD } & \text { sudden cardiac death } \\ \text { SEER } & \text { Surveillance, Epidemiology and End Results }\end{array}$

\section{References}

1. SEER. Surveillance, Epidemiology and End Results (SEER): Stat Fact Sheets: Prostate Cancer. 2008.

2. Bolla M, Gonzalez D, Warde P, Dubois JB, Mirimanoff RO, Storme G, et al. Improved survival in patients with locally advanced prostate cancer treated with radiotherapy and goserelin. N Engl J Med 1997;337:295. [PubMed: 9233866]

3. D'Amico AV, Manola J, Loffredo M, Renshaw AA, DellaCroce A, Kantoff PW. 6-Month androgen suppression plus radiation therapy vs radiation therapy alone for patients with clinically localized prostate cancer: a randomized controlled trial. JAMA 2004;292:821. [PubMed: 15315996]

4. Walsh PC. Immediate versus deferred treatment for advanced prostatic cancer: initial results of the Medical Research Council trial. The Medical Research Council Prostate Cancer Working Party Investigators Group. J Urol 1997;158:1623. [PubMed: 9302187]

5. Barry MJ, Delorenzo MA, Walker-Corkery ES, Lucas FL, Wennberg DC. The rising prevalence of androgen deprivation among older American men since the advent of prostate-specific antigen testing: a population-based cohort study. BJU Int 2006;98:973. [PubMed: 16879443]

6. Shahinian VB, Kuo YF, Freeman JL, Orihuela E, Goodwin JS. Increasing use of gonadotropinreleasing hormone agonists for the treatment of localized prostate carcinoma. Cancer 2005;103:1615. [PubMed: 15742331]

7. Messing EM, Manola J, Yao J, Kiernan M, Crawford D, Wilding G, et al. Immediate versus deferred androgen deprivation treatment in patients with node-positive prostate cancer after radical prostatectomy and pelvic lymphad-enectomy. Lancet Oncol 2006;7:472. [PubMed: 16750497]

8. Lu-Yao GL, Albertsen PC, Moore DF, Shih W, Lin Y, DiPaola RS, et al. Survival following primary androgen deprivation therapy among men with localized prostate cancer. JAMA 2008;300:173. [PubMed: 18612114]

9. Hossain P, Kawar B, El Nahas M. Obesity and diabetes in the developing world-a growing challenge. N Engl J Med 2007;356:213. [PubMed: 17229948]

10. Bessesen DH. Update on obesity. J Clin Endocrinol Metab 2008;93:2027. [PubMed: 18539769] 
11. Vermeulen A, Goemaere S, Kaufman JM. Testosterone, body composition and aging. J Endocrinol Invest 1999;22:110. [PubMed: 10442580]

12. Grinspoon S, Corcoran C, Stanley T, Baaj A, Basgoz N, Klibanski A. Effects of hypogonadism and testosterone administration on depression indices in HIV-infected men. J Clin Endocrinol Metab 2000;85:60. [PubMed: 10634364]

13. Snyder PJ, Peachey H, Hannoush P, Berlin JA, Loh L, Lenrow DA, et al. Effect of testosterone treatment on body composition and muscle strength in men over 65 years of age. J Clin Endocrinol Metab 1999;84:2647. [PubMed: 10443654]

14. Berruti A, Dogliotti L, Terrone C, Cerutti S, Isaia G, Tarabuzzi R, et al. Changes in bone mineral density, lean body mass and fat content as measured by dual energy $\mathrm{x}$-ray absorptiometry in patients with prostate cancer without apparent bone metastases given androgen deprivation therapy. J Urol 2002;167:2361. [PubMed: 11992038]

15. Smith MR, Finkelstein JS, McGovern FJ, Zietman AL, Fallon MA, Schoenfeld DA, et al. Changes in body composition during androgen deprivation therapy for prostate cancer. J Clin Endocrinol Metab 2002;87:599. [PubMed: 11836291]

16. Zamboni M, Mazzali G, Fantin F, Rossi A, Di Francesco V. Sarcopenic obesity: a new category of obesity in the elderly. Nutr Metab Cardiovasc Dis 2008;18:388. [PubMed: 18395429]

17. Smith MR. Changes in fat and lean body mass during androgen-deprivation therapy for prostate cancer. Urology 2004;63:742. [PubMed: 15072892]

18. Smith MR, Lee H, McGovern F, Fallon MA, Goode M, Zietman AL, et al. Metabolic changes during gonadotropin-releasing hormone agonist therapy for prostate cancer: differences from the classic metabolic syndrome. Cancer 2008;112:2188. [PubMed: 18348297]

19. Smith MR, Lee H, Fallon MA, Nathan DM. Adipocytokines, obesity, and insulin resistance during combined androgen blockade for prostate cancer. Urology 2008;71:318. [PubMed: 18308111]

20. Smith JC, Bennett S, Evans LM, Kynaston HG, Parmar M, Mason MD, et al. The effects of induced hypogonadism on arterial stiffness, body composition, and metabolic parameters in males with prostate cancer. J Clin Endocrinol Metab 2001;86:4261. [PubMed: 11549659]

21. Smith MR, Lee H, Nathan DM. Insulin sensitivity during combined androgen blockade for prostate cancer. J Clin Endocrinol Metab 2006;91:1305. [PubMed: 16434464]

22. Lee H, McGovern K, Finkelstein JS, Smith MR. Changes in bone mineral density and body composition during initial and long-term gonadotropin-releasing hormone agonist treatment for prostate carcinoma. Cancer 2005;104:1633. [PubMed: 16116596]

23. Segal RJ, Reid RD, Courneya KS, Malone SC, Parliament MB, Scott CG, et al. Resistance exercise in men receiving androgen deprivation therapy for prostate cancer. J Clin Oncol 2003;21:1653. [PubMed: 12721238]

24. Dockery F, Bulpitt CJ, Agarwal S, Donaldson M, Rajkumar C. Testosterone suppression in men with prostate cancer leads to an increase in arterial stiffness and hyperinsulinaemia. Clin Sci (Lond) 2003;104:195. [PubMed: 12546642]

25. Eri LM, Urdal P, Bechensteen AG. Effects of the luteinizing hormone-releasing hormone agonist leuprolide on lipoproteins, fibrinogen and plasminogen activator inhibitor in patients with benign prostatic hyperplasia. J Urol 1995;154:100. [PubMed: 7539852]

26. Lewington S, Whitlock G, Clarke R, Sherliker P, Emberson J, Halsey J, et al. Blood cholesterol and vascular mortality by age, sex, and blood pressure: a meta-analysis of individual data from 61 prospective studies with 55,000 vascular deaths. Lancet 2007;370:1829. [PubMed: 18061058]

27. Stamler J, Wentworth D, Neaton JD. Is relationship between serum cholesterol and risk of premature death from coronary heart disease continuous and graded? Findings in 356,222 primary screenees of the Multiple Risk Factor Intervention Trial (MRFIT). JAMA 1986;256:2823. [PubMed: 3773199]

28. Third Report of the National Cholesterol Education Program (NCEP) Expert Panel on Detection, Evaluation, and Treatment of High Blood Cholesterol in Adults (Adult Treatment Panel III) final report. Circulation 2002;106:3143. [PubMed: 12485966]

29. Wilt TJ, Bloomfield HE, MacDonald R, Nelson D, Rutks I, Ho M, et al. Effectiveness of statin therapy in adults with coronary heart disease. Arch Intern Med 2004;164:1427. [PubMed: 15249352] 
30. Despres JP, Lamarche B, Mauriege P, Cantin B, Dagenais GR, Moorjani S, et al. Hyperinsulinemia as an independent risk factor for ischemic heart disease. N Engl J Med 1996;334:952. [PubMed: 8596596]

31. Pyorala M, Miettinen H, Laakso M, Pyorala K. Hyperinsulinemia predicts coronary heart disease risk in healthy middle-aged men: the 22-year follow-up results of the Helsinki Policemen Study. Circulation 1998;98:398. [PubMed: 9714089]

32. Keating NL, O'Malley AJ, Smith MR. Diabetes and cardiovascular disease during androgen deprivation therapy for prostate cancer. J Clin Oncol 2006;24:4448. [PubMed: 16983113]

33. Matsuda M, DeFronzo RA. Insulin sensitivity indices obtained from oral glucose tolerance testing: comparison with the euglycemic insulin clamp. Diabetes Care 1999;22:1462. [PubMed: 10480510]

34. American Diabetes Association. Standards of medical care in diabetes-2008. Diabetes Care 2008;31:S12. [PubMed: 18165335]

35. Ferrannini E. Metabolic syndrome: a solution in search of a problem. J Clin Endocrinol Metab 2007;92:396. [PubMed: 17284639]

36. Kahn R, Buse J, Ferrannini E, Stern M. The metabolic syndrome: time for a critical appraisal: joint statement from the American Diabetes Association and the European Association for the Study of Diabetes. Diabetes Care 2005;28:2289. [PubMed: 16123508]

37. Braga-Basaria M, Dobs AS, Muller DC, Carducci MA, John M, Egan J, et al. Metabolic syndrome in men with prostate cancer undergoing long-term androgen-deprivation therapy. J Clin Oncol 2006;24:3979. [PubMed: 16921050]

38. Trujillo ME, Scherer PE. Adiponectin-journey from an adipocyte secretory protein to biomarker of the metabolic syndrome. J Intern Med 2005;257:167. [PubMed: 15656875]

39. Haffner SM. The metabolic syndrome: inflammation, diabetes mellitus, and cardiovascular disease. Am J Cardiol 2006;97:3A. [PubMed: 16675316]

40. Sattar N, McConnachie A, Shaper AG, Blauw GJ, Buckley BM, de Craen AJ, et al. Can metabolic syndrome usefully predict cardiovascular disease and diabetes? Outcome data from two prospective studies. Lancet 2008;371:1927. [PubMed: 18501419]

41. Ferrannini E, Natali A, Bell P, Cavallo-Perin P, Lalic N, Mingrone G. Insulin resistance and hypersecretion in obesity. European Group for the Study of Insulin Resistance (EGIR). J Clin Invest 1997;100:1166. [PubMed: 9303923]

42. American Diabetes Association. Diagnosis and classification of diabetes mellitus. Diabetes Care 2006;29:S43. [PubMed: 16373932]

43. Allibhai SMDHM, Sutradar R, Fleshner NE, Warde P, Cheung AM, Paszat L. Impact of androgen deprivation therapy (ADT) on bone, cardiovascular, and endocrine outcomes: a propensity-matched analysis of 20,000 patients. Unpublished data.

44. Saigal CS, Gore JL, Krupski TL, Hanley J, Schonlau M, Litwin MS. Androgen deprivation therapy increases cardiovascular morbidity in men with prostate cancer. Cancer 2007;110:1493. [PubMed: 17657815]

45. Pilepich MV, Winter K, Lawton CA, Krisch RE, Wolkov HB, Movsas B, et al. Androgen suppression adjuvant to definitive radiotherapy in prostate carcinoma-long-term results of phase III RTOG 85-31. Int J Radiat Oncol Biol Phys 2005;61:1285. [PubMed: 15817329]

46. Efstathiou JA, Bae K, Shipley WU, Hanks GE, Pilepich MV, Sandler HM, et al. Cardiovascular mortality after androgen deprivation therapy for locally advanced prostate cancer: RTOG 85-31. J Clin Oncol 2009;27:92. [PubMed: 19047297]

47. Roach M 3rd, Bae K, Speight J, Wolkov HB, Rubin P, Lee RJ, et al. Short-term neoadjuvant androgen deprivation therapy and external-beam radiotherapy for locally advanced prostate cancer: long-term results of RTOG 8610. J Clin Oncol 2008;26:585. [PubMed: 18172188]

48. Efstathiou JA, Bae K, Shipley WU, Hanks GE, Pilepich MV, Sandler HM, et al. Cardiovascular mortality and duration of androgen deprivation for locally advanced prostate cancer: analysis of RTOG 92-02. Eur Urol 2008;54:816. [PubMed: 18243498]

49. Studer UE, Whelan P, Albrecht W, Casselman J, de Reijke T, Hauri D, et al. Immediate or deferred androgen deprivation for patients with prostate cancer not suitable for local treatment with curative intent: European Organisation for Research and Treatment of Cancer (EORTC) Trial 30891. J Clin Oncol 2006;24:1868. [PubMed: 16622261] 
50. Tsai HK, D'Amico AV, Sadetsky N, Chen MH, Carroll PR. Androgen deprivation therapy for localized prostate cancer and the risk of cardiovascular mortality. J Natl Cancer Inst 2007;99:1516. [PubMed: 17925537]

51. D'Amico AV, Denham JW, Crook J, Chen MH, Goldhaber SZ, Lamb DS, et al. Influence of androgen suppression therapy for prostate cancer on the frequency and timing of fatal myocardial infarctions. J Clin Oncol 2007;25:2420. [PubMed: 17557956]

52. Roach M 3rd. Regarding the influence of adjuvant suppression therapy for prostate cancer on the frequency and timing of fatal myocardial infarction: how real is the risk? J Clin Oncol 2007;25:5325. [PubMed: 18024880]

53. Brown BW, Brauner C, Minnotte MC. Non-cancer deaths in white adult cancer patients. J Natl Cancer Inst 1993;85:979. [PubMed: 8496983]

54. Executive Summary of the Third Report of The National Cholesterol Education Program (NCEP) Expert Panel on Detection, Evaluation, and Treatment of High Blood Cholesterol in Adults (Adult Treatment Panel III). JAMA 2001;285:2486. [PubMed: 11368702]

55. Knowler WC, Barrett-Connor E, Fowler SE, Hamman RF, Lachin JM, Walker EA, et al. Reduction in the incidence of type 2 diabetes with lifestyle intervention or metformin. N Engl J Med 2002;346:393. [PubMed: 11832527]

56. Tayek JA, Heber D, Byerley LO, Steiner B, Rajfer J, Swerdloff RS. Nutritional and metabolic effects of gonadotropin-releasing hormone agonist treatment for prostate cancer. Metabolism 1990;39:1314. [PubMed: 2123281]

57. Smith MR, Malkowicz SB, Chu F, Forrest J, Sieber P, Barnette KG, et al. Toremifene improves lipid profiles in men receiving androgen-deprivation therapy for prostate cancer: interim analysis of a multicenter phase III study. J Clin Oncol 2008;26:1824. [PubMed: 18398147]

\section{APPENDIX}

Adapted ADA recommendations for the diagnosis of prediabetes and diabetes ${ }^{34}$

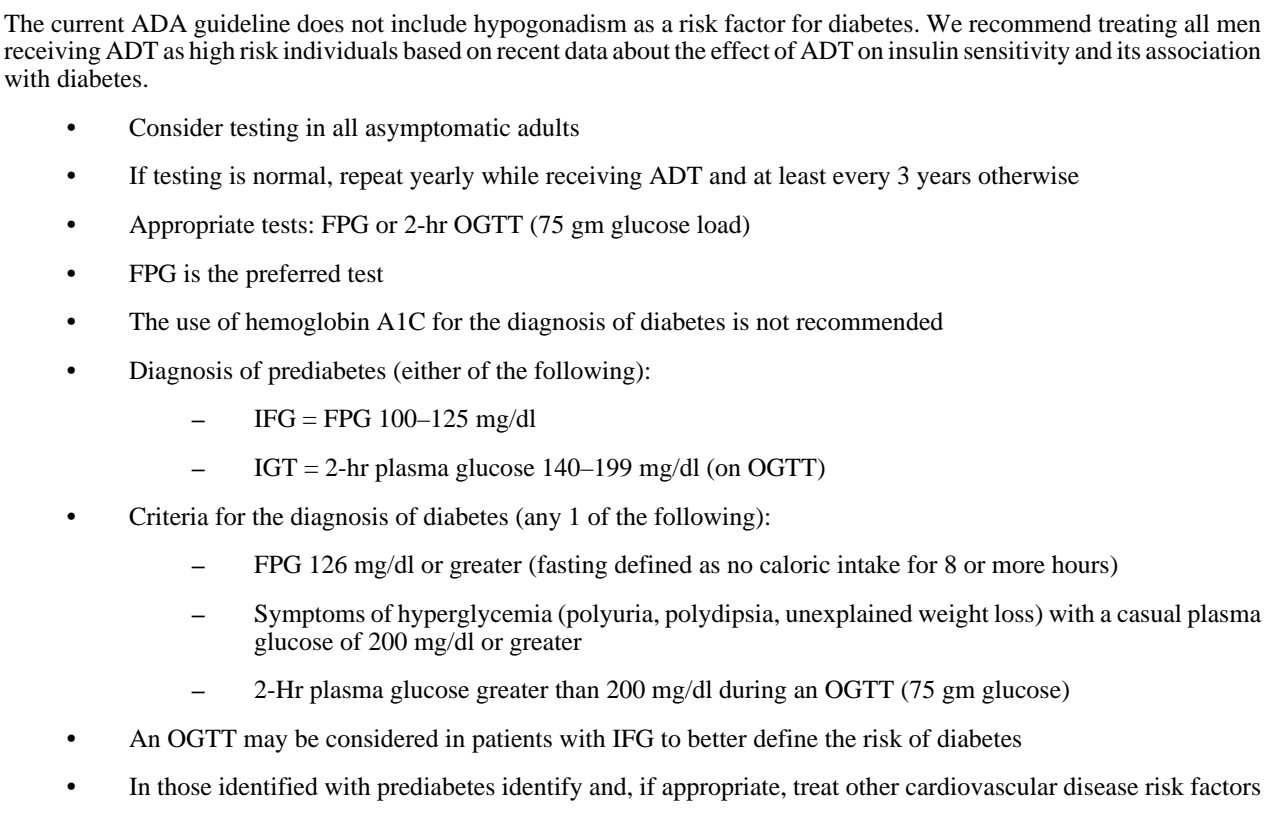



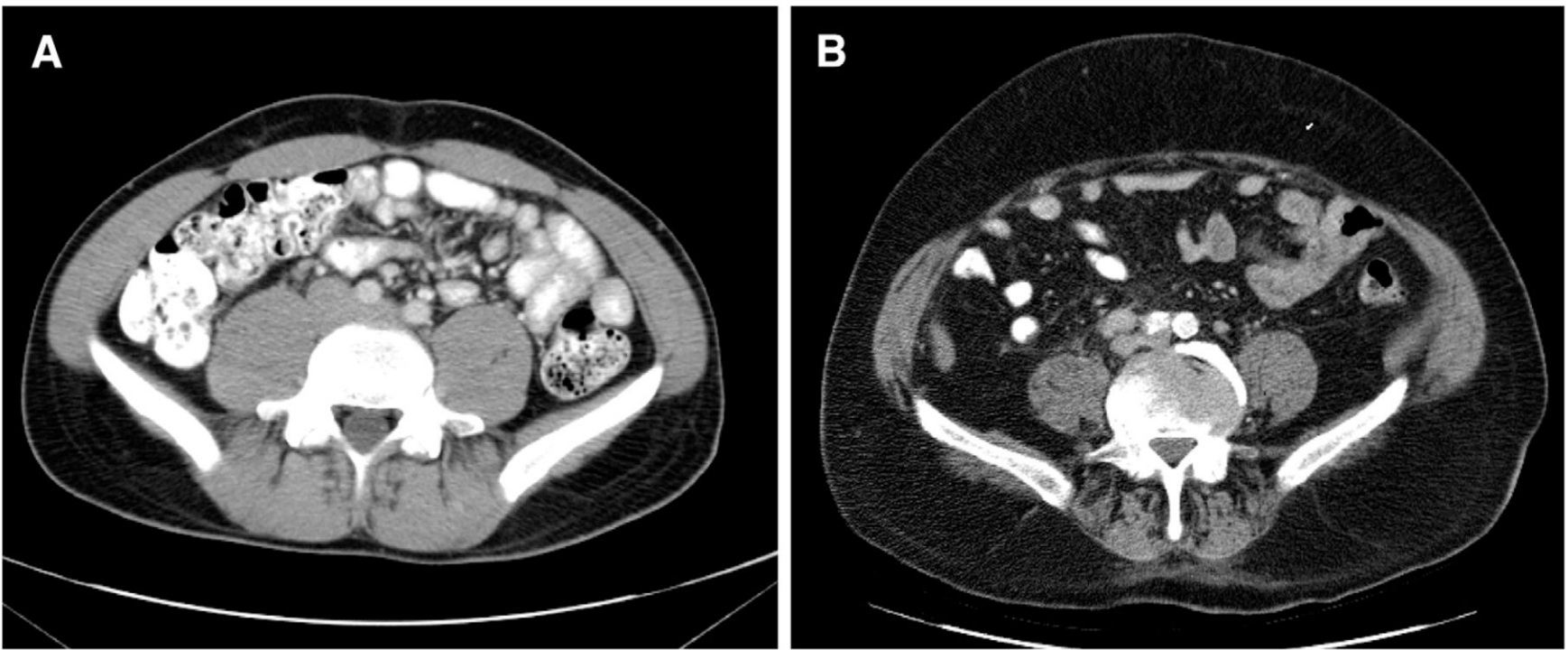

Figure 1.

GnRH agonist associated sarcopenic obesity. GnRH agonists increase abdominal crosssectional area primarily through accumulation of subcutaneous fat. Cross-sectional images of young healthy man $(A)$ and of obese man receiving long-term GnRH agonist therapy $(B)$. Note relative paucity of abdominal and paraspinal musculature, and accumulation of subcutaneous fat. 

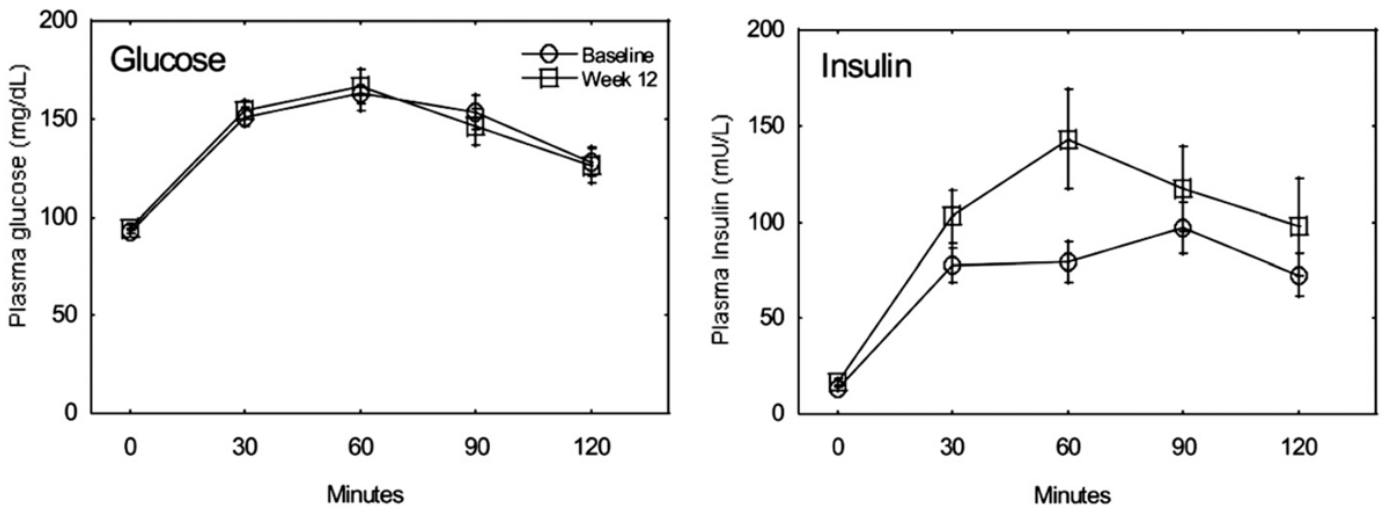

Figure 2.

Insulin sensitivity decreases during GnRH agonist therapy. Glucose and insulin levels throughout oral glucose tolerance test. Data are taken at baseline (circles) and after 12 weeks of androgen blockade (squares). ${ }^{19}$ 
Adjusted Hazard Ratios $\begin{gathered}\text { Excess } \\ \text { Risk value }\end{gathered}$

\section{Diabetes}

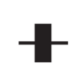

$44 \%<0.001$

Coronary heart disease

Myocardial infarction

$16 \%<0.001$

$11 \%$

0.03

Sudden death

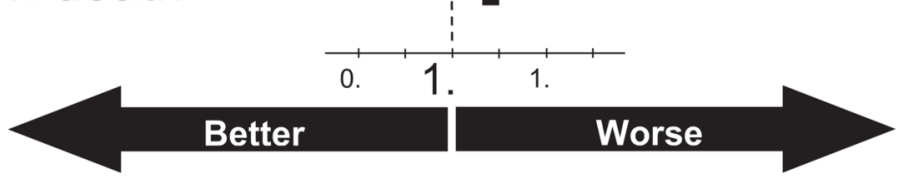

$16 \% \quad 0.04$

Figure 3.

GnRH agonists are associated with significant excess risk of diabetes, coronary heart disease, myocardial infarction and sudden death. Largest excess risk is for diabetes (44\%). ${ }^{32}$ 
Table 1

Prospective data on the metabolic changes caused by ADT

\begin{tabular}{|c|c|c|}
\hline End Points & Observations & Comment \\
\hline \multicolumn{3}{|l|}{ Body composition: } \\
\hline Wt gain & Gain $\sim 2 \%$ in 12 mos $15,17,56$ & $\begin{array}{l}\text { Prospective lifestyle intervention to prevent wt gain } \\
\text { is ongoing }\end{array}$ \\
\hline Fat body mass & Gain $4 \%-8 \%$ in 3 mos, 19,20 gain $\sim 10 \%$ in 12 mos $15,17,18$ & $\begin{array}{l}\text { Subcutaneous abdominal fat area increases while } \\
\text { intra- abdominal fat remains unchanged } 15,18\end{array}$ \\
\hline Lean body mass & Lose $\sim 3 \%$ in first $3-12$ mos $15,17,18,20$ & $\begin{array}{l}\text { Loss of lean body mass with concurrent fat gain } \\
\text { described as sarcopenic obesity }\end{array}$ \\
\hline \multicolumn{3}{|l|}{ Serum lipids: } \\
\hline Total cholesterol & Increases $7 \%-10 \%$ in first 3-12 mos of therapy $15,24,25$ & \\
\hline Triglycerides & Increases $26 \%$ in first $3-6$ mos of therapy 15,25 & \\
\hline HDL & Increases $8 \%-20 \%$ in $3-12$ mos of therapy $15,24,25$ & HDL decreased $\sim 5 \%$ in 12 mos in 1 study 57 \\
\hline LDL & No change in $3-6 \mathrm{mos}^{24,25}$ & Increase of $7 \%$ in first $3 \operatorname{mos}$ in 1 study 15 \\
\hline \multicolumn{3}{|l|}{ Insulin sensitivity: } \\
\hline Fasting insulin & Increases $26 \%-65 \%$ in first $12 \mathrm{wks}^{20,21,24}$ & $\begin{array}{l}\text { Serum glucose does not change significantly in first } \\
3 \operatorname{mos}^{24}\end{array}$ \\
\hline Insulin sensitivity index & Decreases $~ 13 \%$ in 12 wks 19,21 & Calculated from OGTT \\
\hline
\end{tabular}


Table 2

The effects of ADT on clinical end points in population based studies

\begin{tabular}{|c|c|c|c|c|}
\hline Data Source & Population & Events & Results & Comments/Conclusions \\
\hline SEER/Medicare 32 & $\begin{array}{l}73,196 \text { Medicare } \\
\text { enrollees } 66 \text { yrs or } \\
\text { older with } \\
\text { locoregional prostate } \\
\text { Ca, } 64,721 \text { without } \\
\text { prevalent diabetes, } \\
59,748 \text { without } \\
\text { prevalent CHD }\end{array}$ & $\begin{array}{l}\text { Incident diabetes 7,055 (10.9\%), } \\
\text { incident MI 3,917 (5.4\%), } \\
\text { incident CHD 15,116 (25.3\%), } \\
\text { incident SCD 3,301 }(4.5 \%)\end{array}$ & $\begin{array}{l}\text { AHR for incident } \\
\text { diabetes } 1.44(\mathrm{p} \\
<0.001), \text { AHR for } \\
\text { MI 1.11 }(\mathrm{p}=0.03), \\
\text { AHR for CHD } 1.16 \\
(\mathrm{p}<0.001), \text { AHR for } \\
\text { SCD } 1.16(\mathrm{p}=0.004)\end{array}$ & $\begin{array}{l}\text { About } 1 / 3 \text { pts received GnRH } \\
\text { agonists. For men treated with } \\
\text { orchiectomy AHR for diabetes } \\
\text { was } 1.34(\mathrm{p}<0.001) \text { but no excess } \\
\text { risk of MI, CHD or SCD observed }\end{array}$ \\
\hline SEER/Medicare 44 & $\begin{array}{l}22,816 \text { Men } 66 \text { yrs or } \\
\text { older diagnosed with } \\
\text { any stage new prostate } \\
\mathrm{Ca}\end{array}$ & $\begin{array}{l}\text { Serious CV morbidity for men } \\
\text { who received ADT 2,653 }(55 \%)\end{array}$ & $\begin{array}{l}\text { AHR for serious CV } \\
\text { morbidity } 1.20(95 \% \\
\text { CI1.146-1.257) }\end{array}$ & $\begin{array}{l}4,810(21 \%) \text { Men received GnRH } \\
\text { agonists, control cohort was } \\
18,006 \text {; analysis controlled for } \\
\text { age, race, comorbidity score, } \\
\text { history of CHD + other factors }\end{array}$ \\
\hline Canadian database 43 & $\begin{array}{l}\text { Linked databases of } \\
\text { men } 66 \text { yrs or older } \\
\text { with prostate Ca in } \\
\text { Ontario, Canada, } \\
19,709 \text { treated with } 6 \\
\text { or more mos ADT }\end{array}$ & Incident diabetes, incident MI & $\begin{array}{l}\text { AHR for incident } \\
\text { diabetes } 1.16(95 \% \\
\text { CI } 1.11-1.21), \text { AHR } \\
\text { for incident MI0.91 } \\
(95 \% \text { CI } 0.84-1.00)\end{array}$ & $\begin{array}{l}\text { 19,709 Men treated with ADT } \\
\text { matched to similar pts with } \\
\text { prostate Ca not treated with ADT }\end{array}$ \\
\hline CaPSURE $^{50}$ & $\begin{array}{l}\text { Database of men } \\
\text { treated with radical } \\
\text { prostatectomy } 3 \text { ADT }\end{array}$ & Cardiovascular deaths 61 & $\begin{array}{l}5.5 \% \text { with } \\
\text { immediate ADT, } \\
2.0 \% \text { without ADT }\end{array}$ & $\begin{array}{l}\text { Trend toward increased CV } \\
\text { mortality significant only in men } \\
\text { older than } 65 \text { yrs }(\mathrm{p}=0.002 \text { for } \\
\text { that group) }\end{array}$ \\
\hline
\end{tabular}




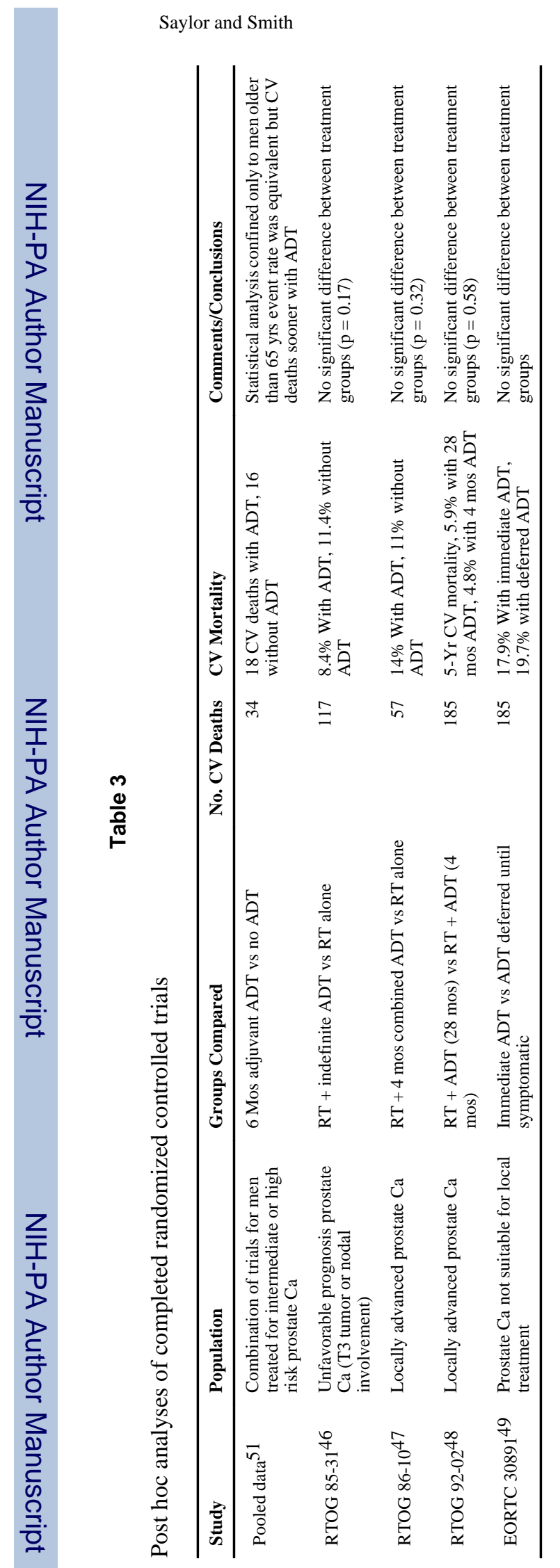

Page 17 